\title{
DIRETIVAS ANTECIPADAS DE VONTADE (TESTAMENTO VITAL): IMPLICAÇÕES ÉTICAS E JURÍDICAS DIANTE DO PRINCÍPIO DA DIGNIDADE DA PESSOA HUMANA
}

\author{
ADVANCE DIRECTIVES OF WILL (LIVING WILL): ETHICAL AND LEGAL \\ IMPLICATIONS BASED ON THE PRINCIPLE OF DIGNITY OF HUMAN PERSON
}

\author{
Maria Aparecida Alkimim ${ }^{1}$ \\ Lino Rampazzo ${ }^{2}$
}

\section{RESUMO}

O presente trabalho, com metodologia de pesquisa filosófica, bibliográfica e documental, pretende aplicar o princípio da dignidade da pessoa humana nas vicissitudes em torno das diretivas de antecipação de vontade, nos aspectos éticos disciplinados pelo Código de Ética Médica, bem como no que se refere aos aspectos jurídicos, envolvendo a Constituição Federal, o Código Civil, o Código de Ética Médica e a Resolução1995/2012 (CFM). O princípio da dignidade da pessoa humana, com a consequente aplicação nos princípios da bioética, é considerado numa perspectiva personalista. Este tipo de abordagem é indicativo da interdisciplinaridade da bioética.

Palavras-chave: Dignidade da pessoa humana; Diretivas antecipadas de vontade; Ética; Direito.

\begin{abstract}
This paper, with methodology of philosophical, bibliographical and documentary research intends to apply the principle of dignity of human person to the vicissitudes around the advance directives of will, to the ethical aspects disciplined by the Code of Medical Ethics, as well as to what regards the legal aspects, involving the Federal Constitution, the Civil Code, the Code of Medical Ethics and the Resolution 1995/2012 (CFM). The principle of dignity of human person along with the consequent application in the principles of bioethics is considered in a personalistic perspective. This kind of approach is indicative of the interdisciplinarity of bioethics.
\end{abstract}

Keywords: Dignity of human person; Advance directives of will; Ethics; Law.

\footnotetext{
${ }^{1}$ Pós-Doutora Pós-Doutor em Democracia e Direitos Humanos (Universidade de Coimbra). Doutora em Direito (PUC/SP). Professora e Pesquisadora no Programa de Mestrado em Direito do Centro Unisal - São Paulo (Brasil). E-mail: maalkimin@ terra.com.br

2 Pós-Doutor em Democracia e Direitos Humanos (Universidade de Coimbra). Doutor em Teologia (PUC Lateranense - Roma). Professor e Pesquisador no Programa de Mestrado em Direito do Centro Unisal - São Paulo (Brasil). E-mail: lino.rampazzo@uol.com.br
} 


\section{INTRODUÇÃO}

O campo de estudo da bioética diz respeito às ciências da vida e da saúde e considera, seja seus princípios originários, procurando uma fundação ética, como os grandes problemas destas ciências, num contexto interdisciplinar. Um destes problemas diz respeito às diretivas de antecipação de vontade, também denominadas de testamento vital.

O presente trabalho, pois, começa considerando o princípio da dignidade da pessoa humana numa perspectiva personalista, e, consequentemente, os princípios da bioética. Em seguida, procura aplicar tais princípios nas vicissitudes em torno das diretivas de antecipação de vontade, nos aspectos éticos disciplinados pelo Código de Ética Médica, bem como no que se refere aos aspectos jurídicos, envolvendo a Constituição Federal, o Código Civil, o Código de Ética Médica e a Resolução1995/2012 (CFM). Estas modalidades de análise são indicativas da interdisciplinaridade da bioética, também nesta problemática específica.

Procurar-se-á particularmente, através de pesquisa documental e bibliográfica, verificar quais são os princípios bioéticos a serem aplicados na atuação profissional do médico diante da situação indicada, inclusive através de uma nova legislação.

\section{O PRINCÍPIO DA DIGNIDADE DA PESSOA HUMANA NUMA PERSPECTIVA PERSONALISTA}

No ano de 2009, a Revista Bioethikós publicou uma entrevista com Elio Sgreccia, Presidente emérito da Pontifícia Academia para a Vida, com o seguinte título: “A Bioética Personalista". Uma das perguntas da entrevista foi a seguinte: como se desenvolveu o conceito de pessoa? Na resposta, Elio Sgreccia, por um lado, afirmava que somente a partir do cristianismo a palavra "pessoa" começou a ser aplicada ao homem; e, por outro, ressaltava que, no último século, os estudiosos da Europa se dedicaram com esforço em reconhecer o personalismo cristão, com a contribuição de Jacques Maritain, Emmanuel Mounier, Étienne Gilson e outros. Além disso, para ele, o personalismo cristão, aplicado na Bioética, valoriza a razão e a fé e reconhece a dignidade da vida humana desde o início até a morte natural. 
De fato, os estudiosos concordam em reconhecer que o conceito de pessoa é estranho à filosofia grega. De fato, o conceito de pessoa acentua o singular, o indivíduo, enquanto a filosofia grega dá importância só ao universal, ao ideal, ao abstrato.

O valor absoluto do indivíduo é um dado da revelação cristã. Ela, pois, não está voltada ao gênero humano de modo abstrato, não diz respeito ao universal, mas é dirigida a todos os homens tomados individualmente, enquanto cada um deles é filho de Deus. No cristianismo, porém, o conceito de pessoa não foi transmitido como um simples dado de fé. Na patrística e na escolástica, ele foi submetido a uma análise racional aprofundada e acabou por adquirir uma sólida veste filosófica.

Percorrendo a história do termo, na antiguidade, seja grega, como romana, o termo “pessoa", em grego prósopon e no latim persona, indicava algo de mutável e não essencial do ser humano: podia ser a mascara de teatro, ou a pessoa gramatical, ou um determinado papel social.

A elaboração do conceito de pessoa se impôs diante da necessidade de "entender" o mistério da Encarnação do Verbo e do mistério da Trindade. Foi determinante, neste sentido, a obra dos Padres Capadócios. Chamam-se "Capadócios" pela região onde eles nasceram (a "Capadócia", situada na atual Turquia) e atuaram, no século IV: e correspondem aos nomes de S. Basílio, S. Gregório de Nissa e S. Gregório Nazianzeno. Os Capadócios admitem, pois, um só Deus, em três pessoas distintas, consubstanciais entre elas. Elas possuem unidade de substância, de operações, de vontade e de ação. Para distinguir as "três" (Pai, Filho e Espírito Santo), eles utilizam o termo hypóstasis; e, para afirmar sua unidade (um único Deus), servemse do termo ousia. Eles, pois, definem ousia como natureza, ou substância comum; e hypóstasis como o aspecto individual de determinação e de distinção. Dessa maneira, o Pai é afirmado na sua característica de princípio, não gerado; o Filho como o gerado e o Espírito Santo como aquele que procede do Pai através do Filho. Daí nasce a fórmula mya ousia, tréis hypostáseis: uma única substancia, três pessoas (MILANO, 1985).

Sucessivamente, os padres do Concílio de Calcedônia (451), tentando definir o "ser" de Jesus Cristo, irão servir-se novamente do conceito de pessoa. Assim, em Jesus Cristo as naturezas humana e divina não se misturam: Ele, na única pessoa divina do Filho de Deus, une, sem misturá-las, as duas naturezas, humana e divina. Por isso, Cristo é, ao mesmo tempo, visível e invisível, sofre e não sofre. 
Em suma, o conceito de pessoa, em Deus, indica a pluralidade (as três pessoas: Pai, Filho e Espírito Santo) e, em Cristo, a unidade (em Jesus Cristo existe uma única pessoa: aquela do Filho de Deus).

Antes, porém, do Concílio de Calcedônia temos a interessante reflexão de S. Agostinho que, pela primeira vez, aplica o conceito de pessoa ao homem. Para ele, o termo grego hypóstasis e ao seu correlativo latino persona (pessoa), "não significa uma espécie, mas algo de singular e de individual (De Trinitate VII, 6. 11). Analogamente este termo aplica-se também ao homem: "Cada homem individualmente é uma pessoa" (singulus quisque homo una persona est) (De Trinitate, XV, 7.11) (AGOSTINHO, 2016). A aplicação do termo "pessoa" ao homem é possível a partir da visão bíblica, que apresenta o homem criado “ à imagem” de Deus (Gen $1,27)$.

Pode-se, então, perguntar qual é o lugar do homem onde se encontra essa imagem de Deus, para S. Agostinho. Essa imagem não está nem no "homem exterior", nem na comunidade familiar, mas na natureza espiritual (secundum rationalem mentem). Ali se acha a verdadeira, ainda que imperfeita, imagem, na medida em que o espírito humano, necessariamente consciente de si, apresenta uma estrutura trinitária essencial na tríade "memória, inteligência e amor" (memória, intelligentia et amor" (De Trin. 15, 22.42; apud GOMES, 1979, p. 293). Segundo Agostinho, os atos intradivinos da geração (o Pai gera o Filho) e da espiração (o Pai e o Filho estão na origem do Espírito) devem ser entendidos como ações espirituais de entender e de amar (apud GOMES, 1979, p. 189-190).

Em suma, a contribuição de Agostinho é decisiva em dois pontos de vista: a descoberta da interioridade e a passagem analógica do conceito de pessoa em Deus à ideia de pessoa aplicada ao homem. A descoberta da interioridade leva o pensamento cristão à certeza de que o eu-pessoa é o centro de decisões livres.

Comparando a evolução do significado do termo "pessoa", seja na língua grega, como na latina, pode-se concluir que se encontra um conteúdo exatamente oposto. Antes "pessoa' indicava as várias identidades que podiam ser aplicadas a um ser humano, em diferentes situações, conforme o papel que precisava desenvolver nestas situações. Mas, no vocabulário cristão, o termo pessoa passa a indicar a irredutível identidade e unicidade de um indivíduo. "Pessoa", indica, pois, aquele centro único de atribuição ao qual fazem referência todas as ações do indivíduo que as unifica em sentido sincrônico, permanecendo diacronicamente "na base", no “substrato" delas. È interessante, a esse respeito, considerar o sinônimo de pessoa: "subsistência”, que, ao pé da letra, significa, pois “o que está debaixo” (CAFFARRA, 2016). 
Esta reflexão está, pois, limitada ao período no qual foi formulado o conceito de pessoa. A partir disso haverá todas as sucessivas reflexões que continuam até os nossos dias.

\section{A BIOÉTICA E SEUS PRINCÍPIOS NA PERSPECTIVA PERSONALISTA}

Na citada entrevista, Elio Sgreccia afirmava que, a partir do personalismo de matriz cristã, estava sistematizando-se o pensamento bioético. E ele, já no ano de 1988, tinha publicado, na língua italiana, um "Manual de bioética", em dois volumes. Atualmente publicado em português na segunda edição (2002). No primeiro volume da obra, ele reserva um capítulo sobre "a pessoa humana e o seu corpo"; e outro sobre "a bioética e seus princípios". Os itens do primeiro capítulo indicado apontam para a perspectiva personalista. Por isso ele desenvolve as seguintes temáticas: "humanizar a medicina", "a pessoa humana e sua centralidade", "o corpo e seus valores", "a transcendência da pessoa"; e aplica esta visão no item "a pessoa, a saúde, a doença”.

No sucessivo capítulo fala explicitamente sobre "os princípios da bioética personalista" (2002, p. 156), a saber: a defesa da vida física, a liberdade e responsabilidade, o Princípio de totalidade ou princípio terapêutico, o Princípio de Socialidade e de Subsidiaridade.

Quanto à defesa da vida física ele afirma que a vida corpórea não exaure toda a riqueza da pessoa que é também, e antes de mais nada, espírito e, por isso, como tal, transcende o próprio corpo e a temporalidade. Todavia, com relação à pessoa, o corpo é co-essencial, é sua encarnação primeira, o fundamento por meio do qual a pessoa se realiza, se expressa e se manifesta. Consequentemente não é possível aceitar a hipótese da supressão direta e deliberada da vida de alguém para favorecer a vida de outros ou as melhores condições político-sociais de outros. E, no âmbito da promoção da vida humana, está inserido o tema da defesa da saúde do homem.

O segundo princípio considera que a liberdade-responsabilidade constitui a fonte do ato ético. Consequentemente, na aplicação bioética, a liberdade-responsabilidade do médico não pode transformar o tratamento em coação, quando a vida não está em questão. É o problema do consentimento do paciente.

O princípio de totalidade, ou princípio terapêutico, fundamenta-se no fato de que a corporeidade humana é um todo unitário resultante de partes distintas e unificadas orgânica e 
hierarquicamente entre si pela existência única e pessoal. O princípio da inviolabilidade da vida, que é primeiro e fundamental, não é negado, mas, ao contrário, posto em prática toda vez que, para salvar o todo, e a própria vida do sujeito, é preciso intervir de maneira mutilante sobre uma parte do organismo. Fundamentalmente, esse princípio regula toda a licitude e a obrigatoriedade da terapia médica e cirúrgica. É por isso que o princípio se chama também princípio terapêutico.

O princípio de socialidade, por sua vez, obriga cada pessoa a se realizar na participação da realização do bem dos próprios semelhantes. No caso da promoção da vida e da saúde, isso importa em que cada cidadão se obrigue a considerar a própria vida e a do outro como um bem não apenas pessoal, mas também social, e obriga a comunidade a promover a vida e a saúde de cada um, a promover o bem comum pela promoção do bem de cada um. Mas, em termos de justiça social, o princípio obriga a comunidade a garantir a todos os meios de acesso aos tratamentos necessários, ainda que seja a custo de sacrifícios dos que estão bem. E é neste momento que o princípio de socialidade se une ao de subsidiaridade, pelo qual a comunidade deve, de uma parte, ajudar mais onde mais grave é a necessidade (ter mais cuidados com quem mais necessita de cuidados e gastar mais com quem está mais doente) e, de outra, não deve suplantar ou substituir iniciativas livres de cada um e dos grupos, mas garantir seu funcionamento.

Em seguida, Sgreccia faz referência à terminologia utilizada na literatura específica sobre bioética, sobretudo a inglesa, na qual se apresentam os princípios de benefício, de autonomia e de justiça. Ele afirma que:

\footnotetext{
indubitavelmente há elementos de validade nesses três princípios e, se observamos bem, poderia haver neles uma correspondência com o princípio terapêutico, o princípio de liberdade e responsabilidade, o princípio de subsidiaridade...Mas se aqueles nos parecem coerentemente unidos entre si por uma antropologia personalista que os fundamenta, que definitivamente faz referência a um bem integral da pessoa,...não ocorre o mesmo com estes. (2002, p. 166-167).
}

A crítica de Sgreccia merece um profundo debate, que não pode ser desenvolvido na brevidade deste artigo, cujo objetivo específico foi o de mostrar um exemplo de aplicação da filosofia personalista de inspiração cristã à bioética. Mesmo assim, no final deste artigo vai ser retomada esta consideração na temática que está sendo desenvolvida.

\section{AUTONOMIA INDIVIDUAL E AUTODETERMINAÇÃO: CONSENTIMENTO LIVRE E ESCLARECIDO}


A autonomia individual e a autodeterminação, que Sgreccia expressou com os termos "liberdade e responsabilidade", constituem atributos inerentes à pessoa humana, tratando-se esse binômio, ao lado da dignidade da pessoa humana, de princípio central e fundamento elementar da bioética, que projeta o indivíduo como sendo soberano sobre si mesmo, de forma que exerce domínio sobre seu corpo e sua mente, ressalvando-se, contudo, que deve estar no gozo da capacidade plena e em plena consciência dos seus atos e vontades.

Para Beauchamp e Childress "a pessoa autônoma é a que não somente delibera e escolhe seus planos, mas é a capaz de agir com base nessas deliberações” (apud DINIZ, 2011, p. 732). Disso decorre o direito de autodeterminação, o qual dá origem, segundo Maria Helena Diniz, "ao dever erga omnes de respeitá-lo, fundamentado no princípio da dignidade da pessoa humana." (2010, p. 732).

Nesse sentido, o paciente que manifesta uma doença terminal e após a informação médica é, sem resquício de dúvida, uma pessoa autônoma, como tal é capaz de deliberar sobre seus objetivos, vontades, desejos, intenções pessoais, devendo agir de acordo com suas deliberações. O indivíduo, como agente moral, tem liberdade de autodeterminar-se, é "senhor absoluto do seu destino" (NAMBA, 2009, p.12).

Portanto, é um desrespeito à autonomia privada do paciente opor-se a seu direito de escolha, negando-lhe a garantia da liberdade de agir com base nas suas deliberações e julgamentos, e desrespeitando, ainda que de forma relativa, a sua dignidade humana.

A liberdade, que abrange a autonomia individual, é um princípio de direito natural, positivado a partir do momento em que foi incorporada na Declaração Universal dos Direitos Humanos e assumiu o status de direito humano e fundamental nas Constituições Democráticas e Liberais, tornando-se princípio-regra que norteia os sistemas jurídicos que disciplinam as relações sociais e jurídicas.

Considera-se que a autonomia e a manifestação do consentimento livre integram a dignidade da pessoa humana, fundamento basilar da República Federativa do Brasil e do Estado Democrático de Direito ( $\mathrm{CF}$, art. $\left.1^{\circ}, \mathrm{III}\right)$; e se encontram positivadas no rol de direitos fundamentais reconhecidos pelo art. $5^{\circ}$. da Constituição Federal que, dentre outros direitos e garantias, prevê a inviolabilidade do direito à vida, à liberdade, à intimidade e à segurança.

A autonomia de vontade e o direito à autodeterminação que emergem da dignidade da pessoa humana e que norteiam pesquisas da biomedicina em seres humanos, invocados, inclusive, pelo Relatório de Belmont de 1979, embasam os princípios norteadores da bioética 
(respeito à pessoa, autonomia, beneficência e justiça) e que deverão ser observados em pesquisas e em manifestação de vontade do paciente, através de testamento vital, por exemplo.

A autonomia na bioética está centrada na filosofia kantiana, para a qual o paciente deve proceder de acordo com sua razão e vontade, onde sua ação se torna lei universal da natureza. Portanto, é fim e não meio na adoção dos procedimento médicos, podendo, inclusive e de forma consciente, recusar tratamento que prolongue sua vida, uma vez comprovado o estado terminal. Isso comprova que cada pessoa tem um valor incondicional em si mesma, assim como possui capacidade de decidir a respeito de seu próprio destino: logo, possui razão, vontade e autodeterminação.

Nesse sentido Kant, ao estabelecer o imperativo categórico que rege a vontade e ação do homem em sociedade, baseou-se na autonomia de vontade individual e na autodeterminação do homem, exaltando-a como princípio universal e regra de direito natural e universal. Este princípio deve prevalecer nas ações humanas, independentemente do modo como são constituídos os objetos do querer, atribuindo-se ao homem, individualmente considerado, a liberdade de escolha do modo como deseja (apud ABBAGNANO, 1998, p. 276).

Importante ponderar que a autonomia, da qual agora se trata, não se confunde com a autonomia absoluta do paciente em pôr termo à própria vida. De fato, o dever imposto pela consciência moral coletiva (DURKHEIM, 2000) impõe que a vida é o bem supremo e está acima da vontade, da autonomia individual: logo os particularismos são rechaçados. Dessa forma, a autonomia não pode ser entendida apenas como autodeterminação, pois deve haver uma ação individual aliada ao componente social, logo a inclusão do outro permite respeito à pessoa, mas sem prejuízo ao interesse social e moral.

À luz de uma interpretação filosófica, o princípio da autonomia deve ser considerado como expressão da liberdade da pessoa em decidir sobre seu destino e resolver sobre seu bemestar, desde que o exercício dessa liberdade não prejudique a liberdade dos outros. Nesse sentido, trata-se de um entendimento com rigor absoluto das premissas tabuladas pela razão pura de Kant. Logo, o paciente tem autonomia ou liberdade de optar, livremente, pelo tratamento que deseja, inclusive, de receber ou optar pelo direito de morrer em paz, negando submissão ao excesso terapêutico de prolongamento da vida.

Assim sendo, prevalece a tendência moderna no sentido de abandonar o paternalismo pelo qual o médico decide o bem-estar do paciente, prevalecendo o critério central do exercício da autonomia onde o paciente busque o seu próprio bem-estar

Para Paul T. Schotsmans: 
[...] devemos conferir valor à vontade da pessoa envolvida no ato biomédico. $\mathrm{O}$ paciente deixa de ser objeto e passa a constituir um ser humano dotado de razão e vontade própria, decidindo, conscientemente, a despeito dos procedimentos que lhes dizem respeito. (2002, p. 24).

Segundo os ensinamentos de Maria Celeste Cordeiro dos Santos, a autonomia ou capacidade de autodeterminar-se faz parte da integridade da pessoa humana, sendo a integridade um atributo de todo ser humano, em qualquer estado em que se encontre, são ou moribundo, que independe da capacidade de autodeterminação. Já a autonomia é um estado de liberdade, privacidade, escolha individual, livre vontade que, ao contrário da integridade, comporta graus, funcionando de acordo com impedimentos internos e externos que refletem na capacidade de manifestação com autodeterminação (1998, p. 93)

Contudo, a capacidade de autodeterminar-se pode sofrer oscilações, inclusive muitas pessoas podem até perder a capacidade de autodeterminação total ou parcialmente devido a doenças, distúrbios mentais ou outros fatores que causem restrições à liberdade de autodeterminação e consciência plena da manifestação de vontade.

Nesse diapasão o consentimento informado e o pleno exercício da autonomia é a base da relação médico-paciente onde ao médico compete prestar as informações em termos adequados, compreensíveis e de forma eficiente, respeitando a liberdade e autodeterminação do paciente. Logo, o processo de tomada de decisão quanto ao bem-estar do paciente não compete com exclusividade ao médico, mesmo diante do princípio da beneficência, visando ajudar o paciente, cuja decisão deve ser uma decisão voluntária, exercida de forma livre por uma pessoa em plena capacidade de consentir sobre seu próprio destino, uma vez submetida ao processo informativo e deliberativo.

De acordo com o Código de Ética Médica (Resolução CFM n. 1931/2009), Capítulo I, inciso XXI, a autonomia do paciente é princípio fundamental que regula a ética na prática médica, dispondo que:

No processo de tomada de decisões profissionais, de acordo com seus ditames de consciência e as previsões legais, o médico aceitará as escolhas de seus pacientes, relativas aos procedimentos diagnósticos e terapêuticos por eles expressos, desde que adequadas ao caso e cientificamente reconhecidas.

Importante trazer a lume a Resolução n. 1.995/2012 do Conselho Federal de Medicina, que dispõe sobre as diretivas antecipadas de vontade dos pacientes, também denominadas de testamento vital. Esta Resolução disciplina a autonomia do paciente no contexto da relação com 
o médico, cuidando da autonomia do paciente nas diretivas em torno de tratamentos médicos que somente prolongam o sofrimento do paciente em estado terminal, sem trazer-lhe benefícios.

A Resolução n. 1.995 prevê também o dever de observância da vontade do paciente que se encontre incapaz de se comunicar ou expressar livremente a sua vontade, manifestada através do representante nomeado pelo paciente antes do estado crítico, cujo mandatário age em nome do mandante.

Frisa-se, contudo, que a Resolução em questão fixou três parâmetros para a validade e eficácia das diretivas antecipadas de vontade: a) a decisão do paciente deve ser feita antecipadamente, ou seja, antes do estado crítico que pode comprometer sua plena consciência; b) o paciente, ao decidir, deve estar no gozo da plena capacidade; e, c) sua manifestação deve prevalecer sobre a vontade dos parentes e dos médicos que o assistem.

Portanto, não deve ser considerado o consentimento manifestado pelo doente que já estiver acometido pela doença e que não disponha de consciência para manifestar sua vontade, tal como pode ocorrer com a existência de patologias psíquicas ou quando forem constatados delírios decorrentes da dor ou influenciados por medicamentos.

Do mesmo modo, a autonomia do paciente e a exteriorização do seu consentimento somente serão validas se manifestadas por pessoa maior e dotada de capacidade civil, devendo ser desconsiderada a vontade manifestada por menores ou incapazes, mesmo que tenha sido expressada pelos seus representantes legais. Deve exprimir vontade séria, livre e esclarecida prestada pelo titular do interesse juridicamente protegido.

\section{O TESTAMENTO VITAL E SUAS IMPLICAÇÕES ÉTICAS E JURÍDICAS}

O testamento vital, ou diretivas antecipadas de vontade, muito embora tenha por finalidade o respeito à autonomia e à autodeterminação do paciente, representa um instituto que causa grandes celeumas em razão de suas implicações éticas, jurídicas e religiosas.

O testamento vital como meio de manifestação da vontade do paciente sobre os tratamentos médicos e meios terapêuticos que serão aplicados para prolongamento da vida, cuja manifestação de vontade em documento escrito implica exigência ou recusa de determinado tratamento, juridicamente considerado, caracteriza o exercício do direito à liberdade e à autonomia privada do paciente que delibera sobre o direito de viver ou morrer dignamente. 
Nesse sentido, deve-se respeitar a intimidade e desejos individuais da pessoa, que tem autonomia para decidir sobre uma morte digna ou manifestar, expressamente, a recusa em receber tratamento ou meios artificiais para prolongamento da vida.

Sob o ponto de vista ético e religioso o paciente, mesmo em estado terminal, deve receber todo tratamento e acompanhamento médico existente e inventado pela medicina que sempre visa a preservação da vida e dignidade no tratamento, não podendo ninguém buscar abreviar a vida, sob pena de caracterizar disposição de um bem indisponível e de interesse público. Por outro lado, diante da dualidade "vida digna e morte digna", a pessoa humana, digna em sua essência humana, uma vez capaz de discernir, tem o direito nato de escolher o tratamento e se deseja prolongar a vida, muitas vezes de forma inútil e irracional.

Pondera-se que o sentido transcendental da dignidade humana abrange o direito de viver, contudo, não exclui o direito de morrer dignamente. Dessa forma, reconhecida a liberdade plena da pessoa humana, deve-se atribuir valor à manifestação de vontade da pessoa humana através de documento escrito onde a mesma declara a vontade de receber ou não determinado tratamento médico, além de ter a liberdade de lançar no documento escrito outras manifestações de vontade, como, funeral, enterro etc.

\subsection{Conceito e finalidade do testamento vital}

O testamento vital é um instrumento de manifestação da autodeterminação em matéria de tratamento médico, também denominado de diretivas, disposições ou diretrizes prévias ou antecipadas, através do qual uma pessoa em situação de lucidez mental e valendo-se de sua autonomia e autodeterminação passa, antecipadamente, instruções sobre tratamentos médicos que deseja ou não deseja receber, caso sofra de uma doença física ou mental incurável ou irreversível que o torne incapaz de exprimir a sua vontade ou de tomar decisões por si e para si própria.

O testamento vital só começou a ser regulado no Brasil após a edição da Resolução $1.995 / 2012$ que passou a conceituar, no seu artigo $1^{\circ}$, o testamento vital ou diretivas antecipadas de vontade dos pacientes "como o conjunto de desejos, prévia e expressamente manifestados pelo paciente, sob cuidados e tratamentos que quer, ou não, receber no momento em que estiver incapacitado de expressar, livre e autonomamente, sua vontade". 
Quanto à forma do testamento vital ou das diretivas de vontade, o enunciado n. 37 aprovado pelo Conselho Nacional de Justiça (CNJ) na I Jornada de Direito de Saúde, dispõe que:

\begin{abstract}
As diretivas ou declarações antecipadas de vontade, que especificam os tratamentos médicos que o declarante deseja ou não se submeter quando incapacitado de expressarse autonomamente, devem ser feitas preferencialmente por escrito, por instrumento particular, com duas testemunhas, ou público, sem prejuízo de outras formas inequívocas de manifestação admitidas em direito. (CNJ, 2014).
\end{abstract}

O testamento vital ou testamento em vida (living will), testamento de vida, cláusulas testamentárias sobre a vida ou testamento biológico, implica autonomia de vontade e autodeterminação do paciente em expressar e formalizar a sua vontade quanto ao tratamento médico, ou seja, inserção de cláusulas através das quais pede que se ministre tratamento adequado para aliviar sofrimento e dor, assim como podem ser inseridas cláusulas com o objetivo de não permitir a utilização de tratamento ou de meios artificiais para prolongar o processo da morte, ou até mesmo para suspender ou interromper o tratamento para proporcionar a morte natural.

O testamento vital também serve para inserir cláusula de conteúdo patrimonial, como também cláusulas sobre enterro, transplante e doação de órgão, além da cláusula de impedimento da eutanásia, sendo que a grande relevância ética e jurídica está na inserção de cláusula de práticas de eutanásia. Contudo, não leva à prática de eutanásia. Trata-se, na verdade, de reconhecimento da dignidade humana e do pleno exercício da liberdade e autonomia de não prolongar a vida sem qualidade e sem dignidade, sendo atentatória à autonomia e dignidade a utilização de recursos artificiais para prolongamento da vida sem qualidade e sem possibilidade de reversão.

Segundo Luciana Dadalto, o testamento vital não tem aplicabilidade somente para casos terminais, também pode ser utilizado para estado vegetativo, doença crônica e degenerativa e previsibilidade de demência avançada e perdas de movimentos voluntários (Alzheimer) (2015, p. 25). Certamente a questão da enfermidade grave, ou estado terminal, tem relevância jurídica na questão do consentimento válido, ou seja, tem que ser elaborado pelo paciente-testador por escrito antes da perda da lucidez.

Também há outra forma de expressão de consentimento e de manifestação da autodeterminação do paciente, que é a nomeação de procurador de cuidados de saúde, através de um documento no qual se atribuem poderes para um procurador adotar decisões sobre os cuidados com a saúde do paciente e também para interpretar o testamento vital diante do quadro 
clínico do testador, quando estiver sem condições de expressar de forma livre e consciente a sua vontade. Juridicamente considerando, é o típico caso de representação por procuração previsto no Código Civil Brasileiro. Contudo, a nomeação do cuidador ou representante legal tem que ocorrer antes da agravação do quadro clínico do paciente-testador.

Pondera-se que o testamento vital ou diretivas antecipadas, produz efeito erga omnes, ou seja, tem efeito vinculante e de imposição em relação ao médico e familiares do pacientetestador e também em relação ao procurador de saúde ou representante legal, cujo efeito vinculante prestigia a autonomia individual e autodeterminação do paciente e, segundo, Luciana Dadalto, evita a “jurisdicialização do morrer” (2015, p. 89), assim como evita discussões em juízo acerca da conduta médica e eventual violação ao Código de Ética Médica.

\subsection{Fundamento ético e jurídico}

O exercício da autonomia e da liberdade condiz com a dignidade da pessoa humana, princípio fundante do Estado Democrático de Direito e que norteia as relações jurídicas. Tal princípio também abrange a dignidade de viver e de morrer, sendo certo que, no exercício da liberdade e autonomia, o paciente pode recusar tratamento fútil ou inútil que vise prolongar a vida, com consequente sofrimento, já que não gerará reversão do estado clínico.

Por outro lado, é princípio fundamental inserido no Código de Ética Médica, aprovado pelo Conselho Federal de Medicina (CFM) que em "situações clínicas irreversíveis e terminais, o médico evitará a realização de procedimentos diagnósticos e terapêuticos desnecessários e propiciará aos pacientes sob sua atenção todos os cuidados paliativos apropriados." (CFM, 2009, Inciso XXII).

Nesse viés, o testamento vital, ou as diretivas antecipadas, visa respeitar o princípio da autonomia de vontade, que se consubstancia na finalidade ética que norteia as sociedades democráticas e pluralistas.

O respeito à autonomia de vontade significa, invocando-se o imperativo categórico de Kant, tratar o paciente como fim em si mesmo e não como meio. Logo, o paciente deve exercer a autodeterminação estabelecendo para médicos e parentes a obrigação de fazer ou de deixar de fazer, diante da irreversibilidade dos efeitos da intervenção médica, valendo-se do testamento vital para expressar em vida a sua vontade no que diz respeito à escolha terapêutica e assistência que devem ser prestadas na fase terminal da vida, buscando evitar sofrimentos inúteis e valorizar a dignidade da pessoa humana. 
Segundo Maria Helena Diniz, o exercício da autonomia e respectivo consenso livre e esclarecido do paciente-testador só pode ser aceito e validado se estiver "fundamentado na informação acessível no nível intelectual e cultural do paciente, na competência, no entendimento e na voluntariedade." (2011, p. 734-735). Continua asseverando que "é direito do paciente a recusa a algum tratamento ou não-aceitação de continuidade terapêutica nos casos incuráveis ou de sofrimento atroz ou, ainda, que possa trazer risco de vida.” (2003, p. 126).

O Código de Ética Médica (CFM, 2009), nos seus artigos 22 e 24, inseridos no Capítulo IV "Direitos Humanos", veda ao médico deixar de obter o consentimento do paciente ou do seu representante legal após esclarecer os procedimentos que serão utilizados (art. 22), assim como veda ao médico deixar de garantir ao paciente "o exercício do direito de decidir livremente sobre sua pessoa e seu bem-estar" (art. 24).

Por outro lado, o mesmo Código respeita a autonomia profissional do médico ao dispor como princípio fundamental que não pode o médico, "em nenhuma circunstância ou sob nenhum pretexto, renunciar à sua liberdade profissional, nem permitir quaisquer restrições ou imposições que possam prejudicar a eficiência e a correção de seu trabalho" (inciso VIII), sendo dever do médico utilizar "todos os meios disponíveis de diagnóstico e tratamento, cientificamente reconhecidos e a seu alcance, em favor do paciente.” (Artigo 32).

Nesse viés, o Código de Ética Médica enaltece o direito à vida, que é um bem a ser respeitado por toda a ordem jurídica. Neste sentido, Maria Helena Diniz afirma que "a vida não é uma concessão jurídico-estatal, nem tampouco um direito a uma pessoa sobre si mesma. Na verdade, o direito à vida é o direito ao respeito à vida do próprio titular e de todos para preservação do convívio social e da ordem pública." (DINIZ, 2003, p. 120).

Logo, haverá aparente conflito entre a autonomia do paciente e a tomada de decisão de acordo com os conhecimentos técnicos e científicos dos médicos e os princípios éticos e normativas do Código de Ética Médica, não afastando a judicialização dessa celeuma.

Inclusive, a própria Resolução CFM n. 1995/2012 em seu artigo $2^{\circ}$, parágrafo $2^{\circ}$, atribui autonomia e liberdade para o médico deixar de levar "em consideração as diretivas antecipadas de vontade do paciente ou representante que, em sua análise, estiverem em desacordo com os preceitos ditados pelo Código de Ética Médica”.

Diante disso, competirá ao Judiciário solucionar os conflitos entre a autonomia de vontade do paciente e a autonomia do médico no exercício pleno da medicina para preservação da vida do paciente. 


\subsection{Autonomia e autodeterminação sob a ótica jurídica}

A autonomia e a autodeterminação sob a ótica jurídica são valores supralegais, atrelados à natureza humana, portanto, constituem extensão da dignidade da pessoa humana. Sob a ótica civilista a autonomia de vontade significa que o "individuo é livre pela declaração de sua própria vontade, em conformidade com a lei, para criar direitos e obrigações." (PEREIRA, 1987, p. 117).

Está expresso no art. 15 do Código Civil que "ninguém pode ser constrangido a submeter-se, com risco de vida, a tratamento médico ou a intervenção cirúrgica." (BRASIL, 2002). Esta norma tem por objetivo preservar a integridade do corpo humano, tutelando a vida que poderá ser exposta a risco em virtude de um tratamento ou cirurgia desnecessária, assim como a autonomia de vontade do paciente.

Por outro lado, é direito do paciente, por meio de testamento vital, recusar algum tratamento ou não aceitar a continuação de tratamento nos casos incuráveis ou de sofrimento atroz, por exemplo, uma vez obtida do médico a informação clara, objetiva, compreensível e detalhada sobre o seu estado de saúde e tratamento a ser seguido, com a autonomia de dar ou não o consentimento livre e esclarecido.

A forma de manifestação dessa autonomia é o testamento vital que se assemelha ao negócio jurídico (ato jurídico), de caráter pessoal, unilateral, revogável e anulável, pelo qual a pessoa expressa a sua vontade, cuja validade opera consequências antes da morte do testador.

Nesse diapasão, o testamento vital, ou diretivas antecipadas de vontade como espécie do gênero negócio jurídico/ato jurídico, deve envolver, necessariamente, à luz do Código Civil Brasileiro, agente capaz, objeto lícito e consentimento válido, ou seja, sem vícios de vontade, conforme se apresenta a seguir.

\subsubsection{Agente capaz: capacidade jurídica}

A capacidade ou competência do paciente para consentir, ou seja, o total discernimento sobre a conduta a ser praticada e a tomada de decisões, é requisito de validade do testamento vital. Portanto, entende-se por competência, conforme os ditames da bioética, a capacidade para decidir autonomamente. Esta decisão tem por base a compreensão da informação transmitida, permitindo exercer a capacidade de efetuar um juízo independente, conforme seu sistema de valores. 
Assim sendo, para a compreensão, formação de juízo de valor e decisão livre e autônoma incumbe ao médico "ao dar esclarecimentos ao paciente para obtenção de seu consenso informado, ater-se à sua personalidade, temperamento e disposição na hora do recebimento da informação relativa ao seu estado clínico...” (DINIZ, 2011, p. 735).

Esses requisitos somam-se à capacidade plena de compreensão das informações recebidas, logo, para a validade do testamento vital (diretivas antecipadas), o paciente-testador deve realizá-lo em pleno estado de consciência, lucidez, para não viciar sua manifestação de vontade, ou seja, seu consentimento informado, cuja manifestação de vontade equivale a uma tomada de decisão, portanto, deve dar-se em estado de plena consciência. Não tem, pois, validade se o paciente estiver em estado psíquico tal que não possa ser considerado capaz de obter uma informação e emitir juízo de valor e decisão.

$\mathrm{Na}$ órbita do Direito Civil, o testamento vital deve ser subscrito por pessoa maior, capaz (capacidade cognitiva, ou seja, de entender e avaliar), perante testemunhas sem relação familiar, nem vínculo patrimonial, com aplicação similar ao testamento, ato de disposição de última vontade regulado pelo Código Civil de 2002, sendo que, neste caso, serão declaradas as últimas vontades que podem consistir em afastar determinados tratamentos de manutenção da vida ou na solicitação de medidas para aliviar sofrimento ou que encurtem o processo de morte.

O testamento vital é uma espécie do gênero negócio jurídico, tratando-se de uma declaração unilateral de vontade, cujo fundamento é a autonomia privada de vontade, logo, envolve agente capaz, objeto lícito e o consentimento válido.

Nos termos do artigo $1^{\circ}$.do Código Civil toda pessoa é capaz de direitos e deveres na ordem civil, distinguindo a capacidade de direito, inerente a toda pessoa humana desde a concepção e o nascimento com vida, da capacidade de fato, efetivo gozo dos direitos, exigindo o consentimento e capacidade plena de discernimento para prática e exercício do direito e, nesse contexto jurídico, devem-se invocar os casos de incapacidade prescritos os artigos $3^{\circ}$. e $4^{\circ}$. do CC. Portanto, o menor de 18 anos não tem capacidade de fato para realizar o testamento vital, como também o demente etc.

Evidentemente, o enfermo ou deficiente mental (art. $3^{\circ}$, II do CC) não tem discernimento para traçar disposições de vontade através de testamento vital ou qualquer outro tipo de disposição de última vontade. Contudo, há uma ambiguidade em relação ao enfermo, posto que a enfermidade por si só não é suficiente para afastar o discernimento total do paciente, ou até mesmo a incapacidade de compreensão e manifestação de vontade por ser momentânea, 
podendo o mesmo ser informado, avaliar e valorar as informações para se manifestar em outro estágio da enfermidade. Portanto, há uma zona cinzenta em certas situações.

Também pode ocorrer que, na ocasião do testamento, a pessoa era capaz, contudo, no momento da execução, perdeu a capacidade de reger os atos da vida civil. Nesse caso, fica uma questão tormentosa, qual seja, o curador especial, nomeado para o incapaz, pode autorizar a execução? Parece que contraria aspectos principiológicos elementares da ordem jurídica, pois a vida é de ordem pública, então merece tutela de forma coletiva, visando o bem coletivo, e também feriria o princípio da indisponibilidade da vida de outrem, assemelhando-se ao auxílio ao suicídio, penalmente tipificado.

\subsubsection{Objeto lícito e consentimento válido}

O testamento vital como ato jurídico, além da capacidade do agente, tem também como requisitos elementares o objeto lícito e o consentimento válido, sob pena de nulidade (art. 166,CC) ou de anulabilidade (art. 177 do CC) do ato jurídico.

Objeto lícito significa aquele que não é contrário à lei ou à moral, aos costumes e à ordem pública. Nesse caso, o direito à vida é um direito indisponível, logo, o direito à vida confunde-se com o dever à vida. Portanto, optar pela morte não condiz com exercício da dignidade humana, não se sobrepondo a liberdade individual sobre a liberdade coletiva.

Contudo o testamento vital, como forma de exercício da autonomia e autodeterminação e prevalência da dignidade humana, deve prevalecer desde que encontre os limites na dignidade da pessoa humana, e isso significa que compete ao paciente o exercício da autonomia para impedir ou suspender tratamentos que prolonguem a vida sem nenhum resultado eficiente e reversível.

O testamento vital, como declaração de vontade, deve ser interpretado de acordo com algumas regras do Código Civil, como por exemplo a regra do art. 122 do CC, onde se atenderá mais à vontade do que ao sentido literal da declaração, portanto, mais valem a vontade e a intenção declaradas.

Nesse viés, o consentimento deve corresponder à manifestação de vontade livre, consciente e de boa-fé, sob pena de gerar vício de consentimento e não produzir nenhum efeito jurídico.

Certamente, a manifestação de vontade através do testamento vital pode se apresentar viciada, tornando a declaração de vontade sem validade jurídica, uma vez presentes os vícios de 
consentimento, tais como: coação, dolo, erro, simulação e fraude. Estes vícios não permitem a declaração válida de vontade, havendo divergência entre a vontade real subjetiva e a vontade declarada.

Dessa forma, para a validade do consentimento, ou seja, da declaração de vontade, o testador deve receber do médico toda informação e esclarecimento acerca da doença, estado clínico e opções terapêuticas, reproduzindo seu consentimento informado, após a compreensão adequada da informação recebida, manifestando a liberdade de decisão sobre seu corpo e sua vida, conforme os próprios valores.

Como negócio jurídico que é, o testamento vital pode ser revogado ou alterado pelo paciente-testador, inclusive em razão de a vontade humana ser oscilante e efêmera, prevalecendo o princípio "in dubio pro vita".

\section{CONCLUSÃO}

A entrevista concedida por Elio Sgreccia em 2009, à Revista Bioethikós, foi uma oportunidade para entender os princípios filosóficos de uma determinada visão da Bioética. Não se pode esquecer de que a bioética se caracteriza pela interdisciplinaridade: mostrou-se, pois, um diálogo entre filosofia, ética e bioética.

Quanto à aplicação dos princípios da bioética no caso específico das diretivas de antecipação de vontade ou o testamento vital, viu-se que corresponde a um instrumento jurídico inserido na ordem jurídica, que disciplina o exercício da autonomia e autodeterminação do paciente em assuntos que dizem respeito ao seu bem-estar e à tomada de decisão quanto ao tratamento a ser utilizado, inclusive na problemática da suspensão e da vedação de tratamentos que prolonguem a vida através de um indevido excesso terapêutico.

Contudo, confrontando a Resolução n. 1995/2012 com o Código de Ética Médica, bem como com o aspecto ético e filosófico do direito à vida, conclui-se que a autonomia do paciente não é absoluta, esbarra na autonomia e na liberdade do médico, contempladas pelo atual Código de Ética Médica, competindo ao Poder Judiciário o papel de utilizar-se da técnica da ponderação para a solução das questões jurídicas em torno do confronto de normas e da aplicação das normas pertinentes à matéria em pauta.

No fundo a crítica de Sgreccia à formulação dos princípios bioéticos de benefício, de autonomia e de justiça, neste caso específico, mostra que a formulação por ele proposta do princípio de "liberdade e responsabilidade" indica mais claramente que a "autonomia" não 
pode ser considerada de maneira absoluta para poder sempre garantir a dignidade da pessoa humana em todas as situações.

Na verdade, há a necessidade de uma lei ordinária e não de uma mera resolução, regulamentando o testamento vital de forma clara e sem confrontações, justamente para implantar a segurança jurídica em matéria de diretivas antecipadas de vontade dos pacientes.

\section{REFERÊNCIAS}

ABBAGNANO, Nicola. Dicionário de Filosofia. Tradução de Alfredo Bosi. 2. ed. São Paulo: Martins Fontes, 1998.

AGOSTINHO, Santo. De Trinitate: libri quindecim. Disponível em: <http://www.augustinus.it/latino/trinita/index2.htm>. Acesso em: 10 ago. 2016.

BELMONT Report. 18 april 1979. Disponível em:

<https://www.ufrgs.br/bioetica/belmont.htm> Acesso em 20 ago. 2016.

BRASIL. Lei $\mathrm{n}^{\mathrm{o}} 10406$ de 10 de janeiro de 2002. Institui o Código Civil. Disponível em: <http://www.planalto.gov.br/ccivil_03/leis/2002/L10406.htm>. Acesso em 20 ago. 2016.

CAFFARRA, Carlo. La persona umana: aspetti teologici. Disponível em: < http://www.caffarra.it/personau_96.php>. Acesso em: 08 ago. 2016.

CONSELHO FEDERAL DE MEDICINA (CFM). Resolução n. 1995/2012, de 31 de agosto de 2012. Dispõe sobre as diretivas antecipadas de vontade dos pacientes. Diário Oficial da União, Brasília, 31 ago. 2013.20 Disponível <http://www.portalmedico.org.br/resolucoes/CFM/2012/1995_2012.pdf>. Acesso em: 10 ago. 2016.

Resolução n. 1931, de 17 de setembro de 2009. Diário Oficial da União, Brasília, 24 set. 2009. Disponível em: < http://portal.cfm.org.br/index.php?option=com_content\&view=category\&id=9\&Itemid=122>. Acesso em: 10 ago. 2016.

CONSELHO NACIONAL DE JUSTIÇA. I Jornada de Direito de Saúde. 14-16 maio 2014. Disponível: em: <http://www.cnj.jus.br/images/ENUNCIADOS_APROVADOS_NA_JORNADA_DE_DIREIT O_DA_SAUDE_\%20PLENRIA_15_5_14_r.pdf>. Acesso em: 10 ago. 2016.

DADALTO, Luciana. Testamento Vital. 3. ed. São Paulo: Atlas, 2015.

DINIZ, Maria Helena. O Estado atual do Biodireito. 8. ed.rev. aum. e atual. São Paulo: Saraiva, 2011. 
Curso de Direito Civil Brasileiro: Teoria Geral do Direito Civil. 27. ed. São Paulo: Saraiva, 2010. v. 1.

Curso de Direito Civil Brasileiro: Teoria Geral do Direito Civil. 20. ed. São Paulo: Saraiva, 2003. v. 1.

DURKHEIM, E. O Suicídio: estudo de sociologia. Tradução de Monica Stahel. São Paulo, Martins Fontes, 2000.

GOMES, Cirilo Folch. A doutrina da Trindade Eterna: o significado da expressão "três pessoas". Rio de Janeiro: Lumen Christi, 1979.

MILANO, Andrea. Trinità. In: BARBAGLIO, Giuseppe; DIANICH, Severino (Orgs.). Nuovo Dizionario di Teologia. 4. ed. Milano: Paoline, 1985. p. 1782-1808.

NAMBA, Edison Tetsuzo. Manual de bioética e biodireito. São Paulo: Atlas, 2009.

PEREIRA, Caio Mário. Instituições de Direito Civil. Vol. I, Rio de Janeiro: Forense, 1987.

SANTOS, Maria Celeste Cordeiro Leite. O equilíbrio de um pêndulo. A bioética e a lei: implicações médico-legais. São Paulo: Ícone, 1998.

SEGRE, Marco; COHEN, Cláudio. Bioética. 2 ed. São Paulo:EDUSP, 1999.

SGRECCIA, Elio. A Bioética personalista. Bioethikós, São Paulo, v. 3, n. 2, p. 265-267, jul./dez. 2009.

Manual de Bioética: I - Fundamentos e Ética Biomédica. Tradução de Orlando Soares Moreira. 2. ed. São Paulo: Loyola, 2002.

SCHOTSMANS, Paul T. O homem como criador? Desenvolvimentos na genética humana e os limites da autodeterminação humana. Cadernos Adenauer, Bioética, Rio de Janeiro, ano 3, v. 1 , maio 2002. 